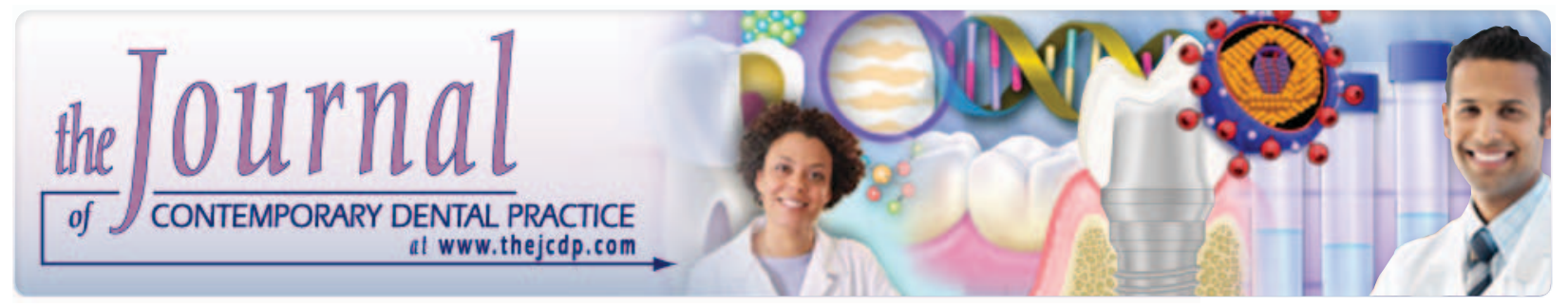

\title{
Microleakage Evaluation of Core Buildup Composite Resins with Total-Etch and Self-Etch Adhesive Systems
}

Horieh Moosavi, DDS, MS; Saied Mostafa Moazzami, DDS, MS; Shaghayegh Loh, DDS; Soheil Salari, DDS

\begin{abstract}
Aim: Core buildup composite resins with prefabricated posts are commonly used to restore endodontically treated teeth. This study compared the sealing ability of Core Max II and Panavia F2.0 cement with total-etch and self-etch adhesive systems.
\end{abstract}

Methods and Materials: Sixty recently extracted human second premolar teeth were chosen and their crowns were cut $3 \mathrm{~mm}$ above the CEJ. After preparing proximal boxes $(4 \pm 1 \mathrm{~mm}$ buccolingually and $3 \mathrm{~mm}$ occlusogingivally dimensions) and finishing root canal therapy, the teeth were randomly divided into four groups $(n=15)$ : groups 1 and 2, Core Max II without and with total-etch adhesive; groups 3 and 4, Clearfil photocore composite, A2 shade, and Panavia F2.0 cement without and with self-etch adhesive respectively. The Dentatus posts (\# 2 Long) were used in canals approximately $8 \mathrm{~mm}$ depth. According to manufacturer guidelines, pins were cemented and cores were restored. After keeping the specimens for 24 hours at $37^{\circ} \mathrm{C}$ and $100 \%$ humidity, they were thermally cycled for 500 cycles, sealed with nail varnish except $1 \mathrm{~mm}$ beyond the margins of restoration, and then immersed in a $0.5 \%$ fuschin basic for 24 hours. Samples were embedded in clear epoxy resin, sectioned mesiodistally, and observed at $20 \times$ magnification. The microleakage was assessed under stereomicroscope and the results were recorded in percentage of dye penetration to the whole path from the cavosurface margin of the proximal boxes to the

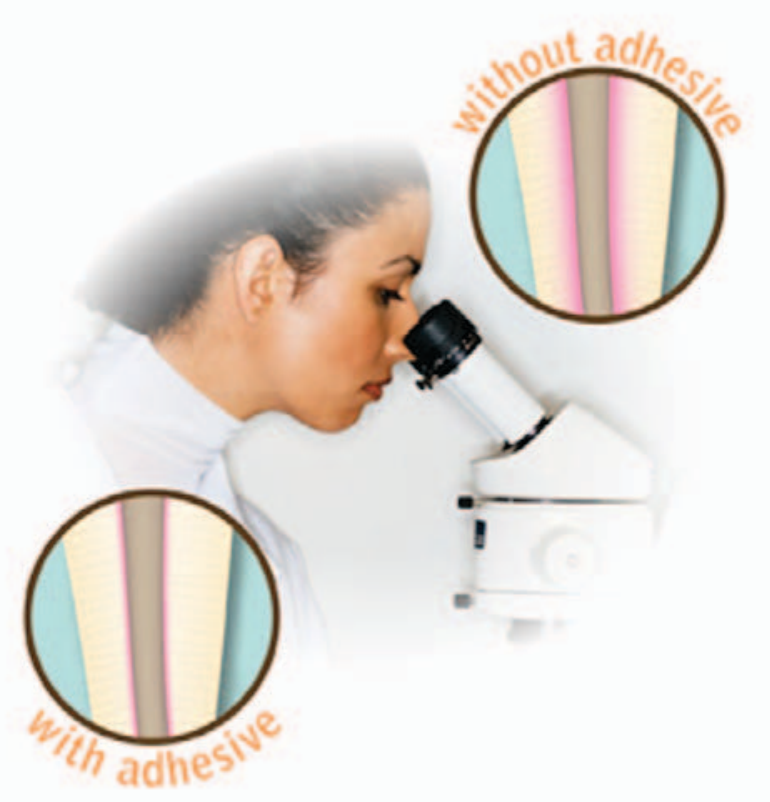

end of the post. Analysis of variance and the Tukey test were used to evaluate the data $(p=0.05)$.

Results: Groups 1 and 4 had the highest and the lowest values of microleakage respectively. Microleakage of Panavia F2.0 cement was lower than for Core Max II and for both cements using adhesive made the microleakage smaller than without it $(p<0.05)$.

Conclusion: Application of adhesive using Core Max II cement and Panavia F2.0 cement is strongly recommended to decrease microleakage. Self-etch adhesive performed better than total-etch adhesive. 
Clinical Significance: With regards to microleakage, the self-etching primer displayed better sealing than that obtained with the totaletching, two-step dental adhesive.

Keywords: Microleakage, core buildup composites, adhesive systems.

Citation: Moosavi H, Moazzami SM, Loh S, Salari S. Microleakage Evaluation of Core Buildup Composite Resins with Total-Etch and SelfEtch Adhesive Systems. J Contemp Dent Pract [Internet]. 2010 March; 11(2):009-016. Available from: http://www.thejcdp.com/journal/view/ volume11-issue2-moosavi.

\section{Introduction}

Restoration in endodontically treated teeth (ETT) is an important aspect of dental practice that involves an assortment of dental options of varying complexity. Dentists have been searching for less expensive and uncomplicated methods with prolonged durability and permanence. ${ }^{1}$ Composite resin post and cores have gained widespread acceptance as an alternative for castgold post and core systems. ${ }^{2}$ Composite cores in conjunction with metallic or nonmetallic posts are widely used to reconstruct ETT and many studies have been conducted on the mechanical properties of these materials, but little information is available on their sealing ability. $\frac{2,3,4}{}$

The main reason for using a post is to retain a core for restoring the missing coronal tooth structure. ${ }^{5.6}$ To obtain the maximum results, the materials that are used to restore ETT should be able to bond to the tooth structure..$^{7}$ Substantial microleakage at the interface between the composite resin core and the dentin substrate may occur. A tight and impervious bond between the dentin and the restorative material is critical for the longevity of core restorations. ${ }^{2}$ Thorough knowledge of dentinal properties is important to better understand the effects of a wide variety of restorative dental procedures and the principles that influence successful integration of tooth and restoration. In addition to apical sealing, coronal sealing is also an important factor because it influences the initiation of secondary caries, as well as the survival rate of posts and restorations, and, ultimately, the failure of endodontic treatment. $\frac{8,9}{9}$

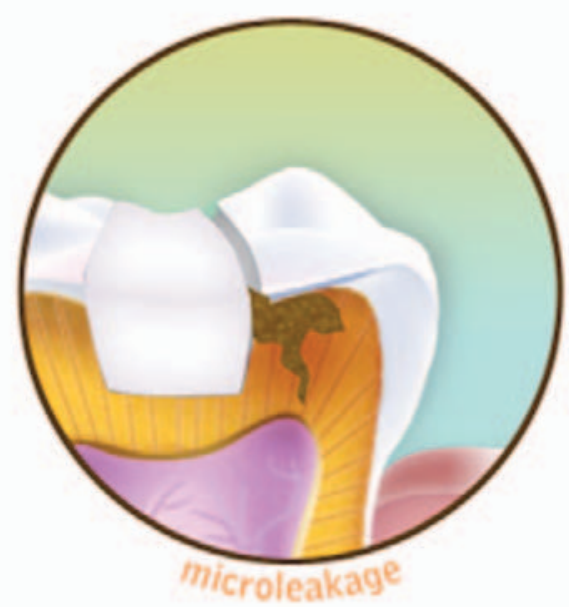

Microleakage is related to the rigidity of the post, the solubility of the cement, and the strength of the adhesive bond between posts and tooth structure. ${ }^{10,11,12}$ Microleakage was influenced by the adhesion between cores and root dentin, more so than the elasticity of each post. Consequently, the adhesion between post and dentin, or between core and dentin, rather than by the other factors, seemed to have an important role in limiting microleakage. ${ }^{13,14}$ Among the various methods of microleakage assessment that were used in previous studies, the quantitative analysis of dye penetration microleakage using an image analyzer was used in the present study and the ratio of dye penetration to the total root area of the post was measured. Therefore, the objective of this study was to evaluate the amount of coronal leakage in two composite core buildup materials, along with applying total-etch and self-etch procedures in human premolar teeth.

The null hypotheses of this study regarding microleakage were

1. Microleakage is identical in four testing groups.

2. Microleakage is identical among the different cements and core buildup materials regardless of total-etch or self-etch mechanisms.

3. Microleakage is identical with or without adhesive application.

\section{Methods and Materials}

Sixty recently extracted human mandibular premolar teeth were selected. The teeth had one canal, lacked any decay or crack, and were kept in normal saline solution in closed-lid containers at room temperature. Any kind of calculus, debris, 
and soft tissue were removed using scalar and pumice powder. In order to comply with infection control protocols, the teeth were immersed in 1\% chloramine solution for two weeks prior to any preparation.

The teeth were then cut $3 \mathrm{~mm}$ above the CEJ by a rotating diamond disk and were placed in small closed-lid containers separately. Mesiodistal boxes with $4 \pm 1 \mathrm{~mm}$ buccolingually and $3 \mathrm{~mm}$ occlusogingivally dimensions were prepared on the teeth. Cervical margins were put $0.5 \mathrm{~mm}$ below the CEJ mesially and distally. Then canals were prepared for the prefabricated Dentatus post (No. 2 long, H. Nordin SA, CH-1816 Chailly-Montreux, Swistzerland) $8 \mathrm{~mm}$ in length from the orifices. The teeth were randomly divided into four groups $(n=15)$. Classification of the groups according to materials and techniques is as follows: Core Max II (Dentsply-Sankin K.K., Japan) without and with Prime and Bond NT (Dentsply) adhesive for cementation of pins and reconstructing cores (groups 1 and 2); Panavia F2.0 (Kuraray America Inc., New York, New York, USA) resin cement without and with ED-primer II $A$ and $B$ adhesive for cementation of pins and Clearfil Photocore (Kuraray America Inc., New York, New York, USA) for reconstructing cores (groups 3 and 4).

In the first group, Core Max II was mixed according to the manufacturer's guidelines, 1 spoon of powder and 4 drops of liquid, for cementation of the pins. For core reconstruction, 1 spoon of powder and 2 drops of liquid were used. In the second group, canals were etched with 34\% phosphoric acid (Dentsply/Caulk, Milford, Delaware, USA) for 15 seconds, rinsed for 10 seconds, and dried with paper cones and air. Then Prime and Bond NT, a total-etch and self-cured adhesive version, was mixed according to the manufacturer's instructions (1 drop of adhesive and 1 drop of activator) and carried with a special microbrush into the canals. All walls of the canal and gingival floor of the preparation were coated with the bonding. Extra adhesive was eliminated by a paper point and then gently air dried. Like the first group, for pin cementation and core reconstruction two different consistencies of Core Max II were used.

In the third group, after cleaning and drying the canals, Panavia F2.0 resin cement was used for post cementation and contrary to the manufacturer's guidelines, its self-etch primer was not applied. An identical amount of paste from each of $A$ and $B$ tubes were placed on the special pad and mixed in a way that initial colors of the pastes disappeared and a homogeneous mixture was formed. All the surfaces of the posts were coated with this paste and placed in the canals by finger pressure for 2 minutes. They were light cured for 3 seconds and the extra paste was cleaned by the tip of an explorer and finally light cured by Optilux 500 (Demetron-Kerr, Orange, California, USA) with $500 \mathrm{~mW} / \mathrm{cm}^{2}$ intensity for 40 seconds. For the fourth group, after cleaning the canal, ED-primer II A and B, a no-rinse, self-priming, and dual-cured dental adhesive, was carried into the canal by a microbrush and applied on the dentin. Extra primer was eliminated by a paper point and gently air dried for three seconds to promote solvent evaporation. The rest of the procedure was as for the third group. In the third and fourth groups, Clearfil Photocore resin composite, A2 shade, was used for core reconstruction. The composite was placed incrementally and cured for 20 seconds at each placement.

The specimens were kept in a $37^{\circ} \mathrm{C}$ incubator with $100 \%$ humidity for 24 hours. They were thermally cycled for 500 cycles of $5-55^{\circ} \mathrm{C}$ with a 30-second dwell time. For evaluating coronal leakage, the apex was sealed with wax and two layers of nail varnish were used on all parts of the tooth except the restored portion and $1 \mathrm{~mm}$ beyond the margins. The teeth were immersed in a $0.5 \%$ basic fuschin solution for 24 hours, rinsed, and embedded in clear epoxy resin. Samples were sectioned mesiodistally through the posts and along the longitudinal axis of the teeth. The prepared sections were evaluated by a SONY stereomicroscope at 20x magnification and were photographed by Asus Digital VCR software. The extent of dye penetration was measured in millimeters along the interface from the proximal cavosurface margins to the apex point of the posts and then divided by the whole length and expressed as percentage. Then the amount of microleakage was measured in millimeters using a standard gauge by ImageJ Launcher software. The side that had a higher dye penetration was figured and the percentage of dye penetration was calculated. The results were statistically analyzed by analysis of variance and the Tukey test. In all cases, $p<0.05$ was considered significant. 
Table 1. Mean values and standard deviations of microleakage percentage in four experimental groups.

\begin{tabular}{|l|c|c|c|c|c|}
\hline \begin{tabular}{|} 
Experimental Groups \\
and Description
\end{tabular} & N & $\begin{array}{c}\text { Mean } \\
\text { Value }\end{array}$ & $\begin{array}{c}\text { Standard } \\
\text { Deviation }\end{array}$ & Minimum & Maximum \\
\hline $\begin{array}{l}\text { Group 1 (Core Max II } \\
\text { without adhesive) }\end{array}$ & 15 & 61.57 & 14.24 & 44.01 & 95.71 \\
\hline $\begin{array}{l}\text { Group 2 (Core Max II } \\
\text { with adhesive) }\end{array}$ & 15 & 40.45 & 9.54 & 12.93 & 53.64 \\
\hline $\begin{array}{l}\text { Group 3 (Panavia F2.0 } \\
\text { without adhesive) }\end{array}$ & 15 & 40.31 & 3.71 & 36.67 & 50.46 \\
\hline $\begin{array}{l}\text { Group 4 (Panavia F2.0 } \\
\text { with adhesive) }\end{array}$ & 15 & 12.37 & 13.85 & 2.23 & 48.44 \\
\hline Total & 60 & 38.68 & 20.72 & 2.23 & 95.71 \\
\hline The result of the tests & & \multicolumn{7}{|c|}{$F=48.9$} & $p$-value< 0.001 & \\
\hline
\end{tabular}

Table 2. The comparisons of the study groups with each other (Tukey test).

\begin{tabular}{|l|c|c|}
\hline \multicolumn{1}{|c|}{ Groups } & Mean Difference & $\boldsymbol{p}$-value \\
\hline G1-G2 & 21.1207 & $p<0.01$ \\
\hline G1-G3 & 21.2573 & $p<0.01$ \\
\hline G1-G4 & 49.2047 & $p<0.01$ \\
\hline G2-G3 & 0.1367 & $p=1$ \\
\hline G2-G4 & 28.0840 & $p<0.01$ \\
\hline G3-G4 & 27.9473 & $p<0.01$ \\
\hline
\end{tabular}

\section{Results}

After gathering and importing the data to SPSS 11.5 software (SPSS Inc., Chicago, Illinois, USA), the Kolmogorov-Smirnov test was done to assure that there was a normal distribution and then the data were analyzed by parametric tests. According to the analysis of variance test, the mean values of microleakage percentage in each group showed a statistically significant difference $(p<0.05$ and $F=48.8)$. The first group had the highest rate of dye penetration percentages $(61.57 \%)$ and the fourth group had the lowest microleakage (12.37\%). So, the first null hypothesis was rejected (Table 1).

The Tukey test demonstrated that all groups, except between the second and third groups, had a statistically significant difference when compared two by two (Table 2).

In order to examine the effects of two factorsthe type of material and the presence or absence of adhesive-two-way analysis of variance was done. The results showed that the kind of material and the existence or lack of adhesive significantly affect the amount of microleakage. Thus, the second and third null hypotheses also were rejected. According to the two-way analysis of variance, Panavia F2.0 cement had reduced microleakage significantly. Mean values and standard deviations of microleakage percentage in Core Max II and Panavia F2.0 were 51.01 \pm 16.0 and $26.3 \pm 17.3$ respectively. This difference was statistically significant $(p=0.001, F=72.545)$. Mean values and standard deviations of microleakage percentage without and with using adhesive were $50.9 \pm 14.8$ and $26.4 \pm 18.4$ respectively $(p=0.001$, $F=71.744)$.

\section{Discussion}

The current study compared the extent of microleakage of two resin cements, Core Max II and Panavia F2.0, with respect to total-etch 
and self-etch adhesive application in ETT premolars. ETT require quick, simple, and lowcost restorations. One of the most important complications of dentistry that has not been solved yet is microleakage..$^{15}$

Endodontic failures primarily result from the presence of bacteria within root canals caused by incomplete root canal preparation or reinfection through a poor coronal seal. ${ }^{16}$ In ETT, the lack of coronal tooth structure often necessitates the placement of a post and core to provide crown retention. In addition to retention, the post also should contribute to a hermetic coronal seal. Microleakage that occurs through a break in the coronal seal is an impeding factor in clinical success. ${ }^{11,17}$

We used a metal post, although it was stated that the fiber-reinforced composite (FRC) posts with composite resin cores showed less microleakage and superior adhesive strength than the prefabricated metal post and core specimens. $\frac{11,18-20}{}$ Just in contrast to a previous study, ${ }^{17}$ the results showed that using Panavia F2.0 with the self-etching mechanism reduced coronal leakage significantly in comparison the two-step, total-etch (Prime and Bond NT) adhesive. Although in coronal dentin, it is established that total-etch adhesives performed better than self-etch adhesives with regard to microleakage, the contrasting result gained in this research. ${ }^{21}$ These differences may be attributed to the structural composition of dentin, the characteristic of the dentinal tubules (density, direction, and dimension) that varies depending on their location within the dentin, thus influencing the response to the type of adhesive system in the root canal dentin compared to the coronal dentin. ${ }^{22}$ Polymerization shrinkage of resin composites may produce contraction forces that can destroy the bond between the dentin and the composite, followed by microleakage and gap formation. $\underline{23}$

Low filler and high resin volume in Core Max II can partially explain the obtained results. High resin volume may cause an increase in the thermal expansion coefficient, polymerization stresses, and more dimensional alterations of resin cements, especially in little thickness while cementing that affects the marginal conformity and results in microleakage increase (increased C-factor).$\stackrel{24}{ }$ Differences in viscosity of the cements

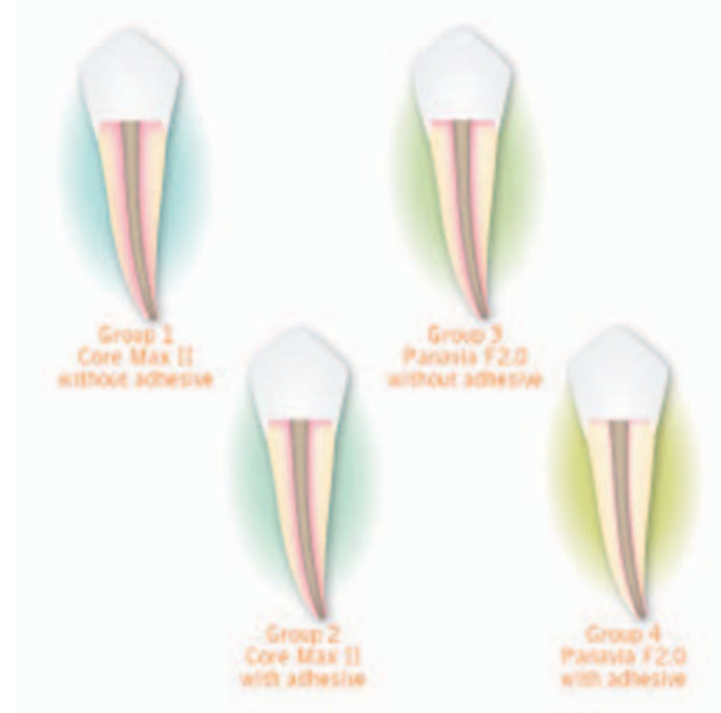

also can affect the seating of dowels and gap formation between tooth, cement, and restoration that leads to dye penetration and a higher amount of microleakage. ${ }^{25}$

Another potential factor that influences microleakage is the type of adhesive system used for bonding of the restoration. ${ }^{26}$ In order to gain adequate bonding, the smear layer that is formed during tooth preparation has to be eliminated or prepared. The effects of various adhesive systems on the smear layer and bonding quality are different. ${ }^{23}$ Since Core Max II is a self-cured resin, a self-cured adhesive also was used because it is contraindicated to use light-cured, one-step, self-etched bonding with self- or dual-cured resin cements or composites. ${ }^{27}$ A statistically significant difference was noticed between using or not using an adhesive with Core Max II. Suitable bonding not only increases core retention, but it also is important in preventing coronal leakage. $\frac{28}{}$ Thus, it is important to minimize the contraction stresses of composites and maintain the soundness and integrity of the tooth and core buildup, even though a crown covers the interface. ${ }^{29}$

According to previous research, waterbased dentin bonding systems showed lower microleakage in dentin margins when compared to acetone-based, water-free dentin bonding systems. ${ }^{30}$ Therefore, the preference of ED-primer/Panavia F2.0, a self-etched primer (water-based solvent), to total-etched Prime and Bond NT adhesive (acetone-based solvent) may be due to the solvent type. Other reasons for the high microleakage level of Core Max II as 
compared to Panavia F2.0 are the application of light polymerization and incremental resin placement for Panavia F2.0 because investigations have shown that self-cured cements and bulky resin placement technique have a higher amount of microleakage than light-cured and incremental placement ones. ${ }^{31}$ Type of tooth structure also can affect the degree of microleakage. Enamel margins, because of the higher volume of minerals, have a better and more acceptable bond than dentin margins, which have a higher content of collagen $\frac{32,33}{2}$ From this research, the test specimen design is not fully a clinically relevant model, and this is a limitation of the study. If these limitations are eliminated, the results would be different. Further studies, inclusive of crowns and force loading, are anticipated to compare the behavior of microleakage.

\section{Conclusion}

Considering the limitations of current studies, it can be concluded that although Core Max II has some advantages such as easy and rapid application in the clinic, compared to Panavia F2.0 with Clearfil Photocore, it has a serious weakness with respect to microleakage. If for any reason we decide to use Core Max II, it must be in conjunction with the appropriate adhesive system: self-/dual-cured bondings, supplied by a credible manufacturer.

\section{Clinical Significance}

With regard to microleakage, the self-etching primer displayed better sealing than that obtained with the total-etching, two-step dental adhesive.

\section{References}

1. Weine FS, Potashnick SR, Strauss S. Restoration of endodontically treated teeth. In: Weine FS, editor. Endodontic therapy. 5th ed. St Louis: Mosby; 1997. p. 764.

2. Tjan AH, Grant BE, Dunn JR. Microleakage of composite resin cores treated with various dentin bonding systems. J Prosthet Dent. 1991; 66(1):24-9.

3. Gish SP, Drake DR, Walton RE, Wilcox
L. Coronal leakage: bacterial penetration through obturated canals following post preparation. J Am Dent Assoc. 1994; 125(10):1369-72.

4. Metzger Z, Schaham G, Abramovitz I, Dotan M, Ben-Amar A. Improving the seal of amalgam cores with cemented dowels: a comparative in vitro radioactive tracer study. J Endod. 2001; 27(4):288-91.

5. Gutmann JL. The dentin-root complex: anatomic and biologic considerations in restoring endodontically treated teeth. J Prosthet Dent. 1992; 67(4):458-67.

6. Saupe WA, Gluskin AH, Radke RA Jr. A comparative study of fracture resistance between morphologic dowel and cores and a resin-reinforced dowel system in the intraradicular restoration of structurally compromised roots. Quintessence Int. 1996; 27(7):483-91.

7. Fernandes AS, Shetty S, Coutinho I. Factors determining post selection: a literature review. J Prosthet Dent. 2003; 90(6):556-62.

8. Saunders WP, Saunders EM. Coronal leakage as a cause of failure in root-canal therapy: a review. Endod Dent Traumatol. 1994; 10(3):105-8.

9. Moosavi H, Maleknejad F, Kimyai S. Fracture resistance of endodontically-treated teeth restored using three root-reinforcement methods. J Contemp Dent Pract. 2008 Jan 1; 9(1):30-7.

10. Lambjerg-Hansen $\mathrm{H}$, Asmussen $\mathrm{E}$. Mechanical properties of endodontic posts. J Oral Rehabil. 1997; 24(12):882-7.

11. Usumez A, Cobankara FK, Ozturk N, Eskitascioglu G, Belli S. Microleakage of endodontically treated teeth with different dowel systems. J Prosthet Dent. 2004; 92(2):163-9.

12. Wu MK, Pehlivan Y, Kontakiotis EG, Wesselink PR. Microleakage along apical root fillings and cemented posts. J Prosthet Dent. 1998; 79(3):264-9.

13. Drummond JL, Bapna MS. Static and cyclic loading of fiber-reinforced dental resin. Dent Mater. 2003; 19(3):226-31.

14. Erkut S, Gulsahi K, Caglar A, Imirzalioglu $P$, Karbhari VM, Ozmen I. Microleakage in overflared root canals restored with different fiber reinforced dowels. Oper Dent. 2008; 33(1):96-105. 
15. Ballal NV. Microleakage of composite resin restorations. Aust Dent J. 2008; 53(4):369-70.

16. Ravanshad S, Ghoreeshi N. An in vitro study of coronal microleakage in endodonticallytreated teeth restored with posts. Aust Endod J. 2003; 29(3):128-33.

17. Mannocci F, Ferrari M, Watson TF. Microleakage of endodontically treated teeth restored with fiber posts and composite cores after cyclic loading: a confocal microscopic study. J Prosthet Dent. 2001; 85(3):284-91.

18. Jung SH, Min KS, Chang HS, Park SD, Kwon $\mathrm{SN}, \mathrm{Bae} \mathrm{JM}$. Microleakage and fracture patterns of teeth restored with different posts under dynamic loading. J Prosthet Dent. 2007; 98(4):270-6.

19. Reid LC, Kazemi RB, Meiers JC. Effect of fatigue testing on core integrity and post microleakage of teeth restored with different post systems. J Endod. 2003; 29(2):125-31.

20. Bell AM, Lassila LV, Kangasniemi I, Vallittu PK. Bonding of fibre-reinforced composite post to root canal dentin. J Dent. 2005; 33(7):533-9.

21. Deliperi S, Bardwell DN, Wegley C.

Restoration interface microleakage using one total-etch and three self-etch adhesives. Oper Dent. 2007; 32(2):179-84.

22. Plotino G, Grande NM, Bedini R, Pameijer CH, Somma F. Flexural properties of endodontic posts and human root dentin. Dent Mater. 2007; 23(9):1129-35.

23. Ferracane JL, Mitchem JC. Relationship between composite contraction stress and leakage in Class V cavities. Am J Dent. 2003; 16(4):239-43.

24. Alster D, Feilzer AJ, de Gee AJ, Davidson CL. Polymerization contraction stress in thin resin composite layers as a function of layer thickness. Dent Mater. 1997;13(3):146-50.

25. Hahn P, Attin T, Gröfke M, Hellwig E. Influence of resin cement viscosity on microleakage of ceramic inlays. Dent Mater. 2001; 17(3):191-6.

26. Maleknejad F, Moosavi H, Shahriari R, Sarabi $\mathrm{N}$, Shayankhah $\mathrm{T}$. The effect of different adhesive types and curing methods on microleakage and the marginal adaptation of composite veneers. J Contemp Dent Pract. 2009 1;10(3):18-26.

27. Kimyai S, Oskoee SS. Effect of 1-bottle lightcured adhesive acidity on microleakage of a self-cured composite. Oper Dent. 2006; 31(6):694-8.

28. Ray HA, Trope M. Periapical status of endodontically treated teeth in relation to the technical quality of the root filling and the coronal restoration. Int Endod J. 1995; 28(1):12-8.

29. Chutinan S, Platt JA, Cochran MA, Moore BK. Volumetric dimensional change of six direct core materials. Dent Mater. 2004; 20(4):345-51.

30. Toman $M$, Toksavul $S$, Artunç $C$, Türkün $M$, Schmage P, Nergiz I. Influence of luting agent on the microleakage of all-ceramic crowns. J Adhes Dent. 2007; 9(1):39-47.

31. Saunders WP, Strang R, Ahmad I. Effect of composite resin placement and use of an unfilled resin on the microleakage of two dentin bonding agents. Am J Dent. 1990; 3(4):153-6.

32. Ferrari M, Dagostin A, Fabianelli A. Marginal integrity of ceramic inlays luted with a selfcuring resin system. Dent Mater. 2003; 19(4):270-6.

33. Sorensen JA, Dixit NV, White SN, Avera SP. In vitro microleakage of dentin adhesives. Int J Prosthodont. 1991; 4(3):213-8.

\section{About the Authors}

\section{Horieh Moosavi, DDS, MS (Corresponding Author)}

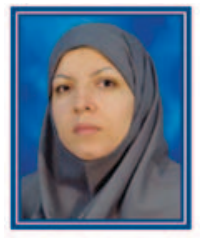

Dr. Moosavi is an assistant professor of Operative Dentistry, Dental Research Center of Mashhad University of Medical Sciences, Iran. Her research interests include microleakage, adhesive systems, and tooth-colored restorative materials. She is a member of the Iranian Academy of Cosmetic Restorative Dentistry and an IADR member in the USA. She has been the corresponding author for this article.

e-mail: dentist 57@yahoo.com or moosavih@ mums.ac.ir

\section{Saied Mostafa Moazzami, DDS, MS}

Dr. Moazzami is an associate professor of

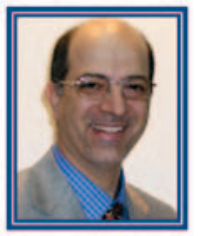
Operative and Esthetic Dentistry, Dental Research Center of Mashhad University of Medical Sciences, Iran. His research interests include microleakage, adhesive systems, and tooth-colored restorative materials.

$\mathrm{He}$ is a member of the Iranian Academy of Cosmetic Restorative Dentistry.

e-mail: moazzamism@mums.ac.ir 


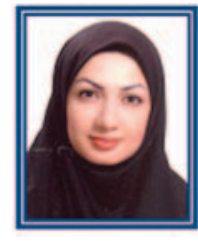

Dr. Loh is a general dentist. Her field of interest is pediatric dentistry, especially about patient control and anti-caries vaccine.

e-mail: shaghayeghloh@gmail.com

Soheil Salari, DDS

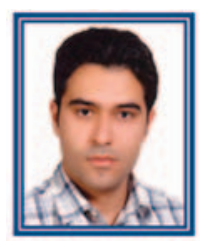

Mr. Salari is a postgraduate student of Orthodontics, Dental Research Center of Mashhad University of Medical Sciences, Iran. His interests include new bonding systems and new methods of tracing cephalometries.

e-mail: Soheilsalari@gmail.com

\section{Acknowledgement}

The authors would like to thank the research vice chancellor of Mashhad University of Medical Sciences for their cooperation and financial support. This article is extracted from thesis No \#2163 and research protocol code No \# 86068. 